\title{
Is Breast Surgery Necessary for Breast Carcinoma in Complete Remission Following Neoadjuvant Chemotherapy?
}

\section{Ist eine Operation der Brust bei Komplettremission nach neo- adjuvanter Chemotherapie des Mammakarzinoms notwendig?}

\section{()(1) $(8 \ominus$}

\section{Authors}

Hannah Richter ${ }^{1}$, André Hennigs ${ }^{1}$, Benedikt Schaefgen ${ }^{1}$, Markus Hahn², Jens Uwe Blohmer ${ }^{3}$, Sherko Kümmel ${ }^{4}$, Thorsten Kühn ${ }^{5}$, Marc Thill ${ }^{6}$, Kay Friedrichs ${ }^{7}$, Christof Sohn ${ }^{1}$, Michael Golatta ${ }^{1}$, Jörg Heil ${ }^{1}$

Affiliations

1 Brustzentrum der Universitäts-Frauenklinik Heidelberg, Heidelberg, Germany

2 Department für Frauengesundheit, Universitätsklinikum Tübingen, Tübingen, Germany

3 Brustzentrum der Klinik für Gynäkologie, Campus Charité Mitte, Berlin, Germany

4 Brustzentrum der Kliniken Essen-Mitte, Evang. HuyssensStiftung/Knappschaft GmbH, Essen, Germany

5 Klinik für Frauenheilkunde und Geburtshilfe, Klinikum Esslingen GmbH, Esslingen, Germany

6 Brustzentrum, Agaplesion Markus Krankenhaus, Frankfurt am Main, Germany

7 Mammazentrum am Krankenhaus Jerusalem Hamburg, Hamburg, Germany

Key words

neoadjuvant chemotherapy, minimally invasive biopsies, breast cancer, diagnosis, surgery

Schlüsselwörter

neoadjuvante Chemotherapie, minimalinvasive Biopsie, Brustkrebs, Diagnose, Operation/Chirurgie

received 22.9.2017

revised 2.12.2017

accepted 3.12.2017

Bibliography

DOI https://doi.org/10.1055/s-0043-124082

Geburtsh Frauenheilk 2018; 78: 48-53 @ Georg Thieme

Verlag KG Stuttgart · New York | ISSN 0016-5751

Correspondence

Prof. Dr. Joerg Heil

Brustzentrum der Universitäts-Frauenklinik Heidelberg Im Neuenheimer Feld 440, 69120 Heidelberg, Germany joerg.heil@med.uni-heidelberg.de
Deutsche Version unter:

https://doi.org/10.1055/s-0043-124082

\section{ABSTRACT}

The likelihood of pathological complete remission (pCR) of breast cancer following neoadjuvant chemotherapy (NACT) is increasing; most of all in the triple negative and HER2 positive tumour subgroups. The question thus arises whether or not breast surgery is necessary when there is complete remission after NACT, and whether it provides any improvement of the oncological treatment result when tumour is no longer detectable. Avoiding surgery and possibly even radiotherapy would only be conceivable on the basis of a reliable diagnosis of pCR without operating. Current imaging does not achieve the necessary sensitivity and specificity to assure the diagnosis of pathological complete remission. Further studies are therefore required to determine which methods are best able to evaluate tumour response to NACT. Studies on imageguided, minimally invasive biopsies after NACT have delivered first promising results towards diagnosing $\mathrm{PCR}$ before surgery and could provide the basis for further studies on the possibility of avoiding surgery in this specific patient collective.

\section{ZUSAMMENFASSUNG}

Die Wahrscheinlichkeit einer pathologischen Komplettremission ( $\mathrm{pCR}$ ) bei Brustkrebs nach neoadjuvanter Chemotherapie (NACT) nimmt zu; vor allem in den Subgruppen der tripel-negativen und HER-2-positiven Tumoren. Daher stellt sich die Frage, ob bei einer Komplettremission nach NACT eine operative Therapie der Brust notwendig ist, und ob es einen Vorteil für das onkologische Behandlungsergebnis hat, wenn kein Tumor mehr nachgewiesen werden kann. Ein Verzicht auf die Operation und gegebenenfalls auch auf die Radiotherapie ist jedoch nur auf der Basis einer verlässlichen pCR-Diagnose ohne Operation denkbar. Bildgebende Verfahren erreichen derzeit nicht die nötige Sensitivität und Spezifität, um die Diagnose einer pathologischen Komplettremission sicher zu stellen. Daher sind weitere Studien nötig, um herauszufinden, 
welche Methode die bestmögliche Evaluation des Tumoransprechens auf NACT erlaubt. Erste vielversprechende $\mathrm{Er}$ gebnisse zeigen sich in Studien zu bildgebungsgesteuerten, minimalinvasiven Biopsien nach NACT. Diese evaluieren die
Möglichkeit einer pCR-Diagnose vor der Operation und könnten die Grundlage für weitere Studien zu einem möglichen Verzicht auf eine Operation in diesem ausgewählten Kollektiv sein.

\section{Introduction and Background}

In recent years neoadjuvant chemotherapy regimes (NACT) for the treatment of breast carcinoma have become more and more effective. As a consequence there has been a significant increase in rates of pathological complete remission $(P C R)$ particularly in the triple negative and HER2 positive tumour subgroups where pCR rates of up to $60 \%$ have been achieved. Also, knowledge about the relationship between tumour biology, achieving pathological complete remission (pCR) and improved prognosis has increased significantly. The point has been reached where, in the context of routine clinical practice, both doctors and patients are you asking the question whether an operation, i.e. breast and lymph node resection (or partial resection), and locoregional radiotherapy are necessary.

The aims of surgery following NACT are therapeutic on the one hand, and diagnostic on the other: therapeutic removal of possible residual tumour from the breast, aiming for complete locoregional tumour resection, and acquiring diagnostic information regarding tumour response to NACT. The latter is only possible through histopathological examination of the resected tissue since imaging studies are known to be inadequate. In view of increasing $\mathrm{PCR}$ rates the following questions are raised:

1. Can available diagnostic methods predict complete remission with a high level of certainty? This would be an essential prerequisite for studies aiming to answer the next question;

2. Can surgery be avoided in the context of pCR, or is it still a therapeutic necessity?

Currently there are good grounds not to avoid surgery. Tumour remission cannot be confirmed with enough certainty using imaging, so an operation remains indispensable for diagnostic purposes. New study concepts tackle this problem by attempting to show definite tumour remission using percutaneous, minimally invasive biopsy.

This article summarises the current status of imaging for the assessment of treatment response of breast lesions to NACT (NB: nodal status not considered in this article). In addition, current and planned studies on the diagnosis of pCR in the breast (ypT0) using percutaneous, minimally invasive biopsy techniques are presented. Historical studies are discussed in which locoregional treatment was modified after NACT.

\section{Historical Studies on Adapting Locoregional Therapeutic Management}

Earlier studies on adapting locoregional therapy were conducted in an age when high quality breast imaging was not available and our understanding of intrinsic tumour subtypes and their individ- ual responses to NACT was poorly developed. Thus, from today's perspective they appear to have been doomed to fail. The clinical assessment of tumour response in the described studies was nonuniform and inexact, and pathological complete remission could not be predicted. The results of earlier studies are shown in $\mathbf{r a} \mathbf{T a}$ ble 1; these studies are very inhomogeneous, evaluating various locoregional treatment strategies only some of which were guided by tumour response to neoadjuvant therapy ( $\vee$ Table 1 ). Even the definition of clinical complete remission (cCR) varied significantly between the studies. Ellis et al. 1998 [1] based the diagnosis of $\mathrm{CCR}$ on the complete absence of a palpable breast lesion following NACT. In this study a collective of 185 breast cancer patients were evaluated with respect to various prognostic factors. 39 patients with clinical complete remission chose not to undergo surgery and were treated with radiotherapy alone. The local recurrence rate in this group was $21 \%$ compared to only $7 \%$ in the group undergoing surgery (28 cCR cases [19.2\%] of 146 patients in the operative group).

Two studies ( $\triangleright$ Table 2 ) had the primary aim of evaluating locoregional radiotherapy as a definitive treatment option compared to surgery in patient collectives with clinical complete remission (cCR) following NACT. In some instances there were high locoregional recurrence rates so that in these studies too, this treatment strategy appears unacceptable. Nevertheless, these historical results must be considered taking the above-mentioned diagnostic limitations, the limited general understanding of the disease situation in the past and significant differences to current systemic treatments into account. These studies probably only allow the conclusion that in these study collectives, physical examination and imaging were not able to identify the group of patients with minimal, residual or even absent tumour cells. For example, in the study by Ring et al. in 2003 [2] only $25 \%$ of patients with $c C R$ had $p C R$. Preoperative investigations (clinical examination and imaging) were thus not accurate enough to definitely identify patients with pCR. Even today imaging does not provide sufficient certainty. In current routine clinical practice only approximately two thirds of cases with cCR are ultimately diagnosed with PCR [3]. This is certainly an improvement on earlier study findings, however these results are still certainly insufficient to allow avoidance of surgery or the planning of a prospective study on operation avoidance.

\section{The Level of Diagnostic Certainty of Imaging in the Assessment of Remission}

The sensitivity and specificity of imaging for predicting PCR is inadequate, i.e. neither $\mathrm{PCR}$ nor residual tumour can be predicted with certainty [11-14]. In addition, the various studies differ greatly in terms of imaging methods and even the definition of 
- Table 1 Overview of previous studies evaluating locoregional treatment regimens, adapted from [4].

\begin{tabular}{|c|c|c|c|c|c|c|c|}
\hline \multirow[t]{2}{*}{ Study } & \multirow{2}{*}{$\begin{array}{l}\text { Study } \\
\text { period }\end{array}$} & \multirow[t]{2}{*}{ n } & \multirow[t]{2}{*}{ CCR } & \multicolumn{2}{|l|}{ Locoregional therapy } & \multicolumn{2}{|l|}{ 5-year LRR } \\
\hline & & & & Operation & Only RT & Operation (\%) & Only RT (\%) \\
\hline De Lena et al. [5] & $\begin{array}{l}1975-1980 \\
\text { prospective }\end{array}$ & $\begin{array}{l}132 \\
(\mathrm{~T} 3 \mathrm{~b}-4, \mathrm{~N} 0-2)\end{array}$ & $\begin{array}{l}100 \% \text { of RT group, } \\
60 \% \text { of operation group }\end{array}$ & 65 & 67 & 29.6 & 31.1 \\
\hline Perloff et al. [6] & $\begin{array}{l}1978-1983 \\
\text { prospective }\end{array}$ & 87 & $18 \%$ & 43 & 44 & 19 & 27 \\
\hline Scholl et al. [7] & 1986-1990 & 200 & $?$ & $\begin{array}{l}36 \mathrm{mtx} \pm \mathrm{RT}, \\
62 \mathrm{BCT}+\mathrm{RT}\end{array}$ & 102 & 24 & \\
\hline Touboul et al. [8] & $\begin{array}{l}1982-1990 \\
\text { prospective }\end{array}$ & 97 & 33 & $\begin{array}{l}37 \mathrm{rD}(>3 \mathrm{~cm}), \mathrm{mtx} \\
27 \mathrm{rD}(<3 \mathrm{~cm}), \mathrm{BCT}\end{array}$ & 33 & $\begin{array}{l}16 \text { after } \mathrm{BCT} \\
5.4 \text { after } \mathrm{mtx}\end{array}$ & 16 \\
\hline Ellis et al. [1] & 1985-1994 & 185 & 39 & 120; 29 mtx, 91 BCT & 39 & 7 & 21 \\
\hline Maruiac et al. [9] & 1985-1989 & $134(\mathrm{~T} 2-3)$ & & $\begin{array}{l}89 ; 40 \mathrm{BCT}=\mathrm{RT}, \\
49 \mathrm{mtx}\end{array}$ & 44 & $\begin{array}{l}22.5 \mathrm{BCT}+\mathrm{RT} \\
22.4 \text { after } \mathrm{mtx}\end{array}$ & 34 \\
\hline
\end{tabular}

BCT: breast conserving therapy, CCR: clinical complete remission, LRR: locoregional recurrence rate, mtx: mastectomy, rD: residual disease, RT: radiotherapy

- Table 2 Overview of previous studies evaluating radiotherapy as the only locoregional therapy in the context of cCR, adapted from [4].

\begin{tabular}{|l|l|l|l|l|l|l|}
\hline Study & $\begin{array}{l}\text { Study } \\
\text { period }\end{array}$ & $\mathbf{n}$ & cCR & \multicolumn{2}{l|}{ Locoregional therapy } & 5-year LRR \\
\hline & & & & Operation & Only RT & Operation (\%) \\
\hline Ring et al. [2] & $1986-1999$ & 453 & 136 & 67 & 69 & 10 \\
\hline Daveau et al. [10] & $1985-1999$ & 1477 (T2-3) & 165 & 65 & 100 & 12 \\
\hline cCR: clinical complete remission, LRR: locoregional recurrence rate, RT: radiotherapy \\
\hline
\end{tabular}

complete remission. Standardised criteria exist for complete remission on imaging, however these use evaluation criteria for solid tumours in general and do not describe details specific to breast imaging [15]. The majority of studies to date have the estimation of residual tumour size on imaging as their endpoint. More recently a number of studies have attempted to improve the prediction of pCR using imaging (MRI, mammography, ultrasound). These studies calculate false negative rates (FNR) and negative predictive values (NPV), which are regarded as the most informative indices for diagnostic certainty in this context (comparison in - Table 3). The NPV in these analyses is equivalent to the total number of cases with clinical complete commission on imaging (cCR) and pCR on resected breast tissue (all truly negative cases) divided by total number of cases with cCR. The FNR is the quotient of false negative cases (cCR on imaging but residual tumour in resected breast tissue) divided by the total number of cases with residual tumour cells in resected breast tissue. The various study results demonstrate that the diagnostic accuracy of imaging remains unsatisfactory for this day and age. Of the imaging modalities magnetic resonance imaging achieves the highest accuracy with NPV between 44 and $94 \%$. When the different tumour subtypes are compared there is a recognisable tendency towards higher NPVs among patient groups with triple negative and HER2 positive tumours $[16,17]$.
Mammography and ultrasound (US) of the breast are the most commonly used imaging modalities for the determination of tumour size following initial diagnosis. Their accuracy is, however, limited in estimating tumour size following NACT. Tumour characteristics often change during chemotherapy: tumour fibrosis and fragmentation occur, tumour density changes and sometimes intraductal, in situ components remain after the disappearance of invasive tumour components. Intraductal tumour components can also be eliminated by NACT. However, microcalcification that may be present usually appears unchanged following NACT [2427]. Despite all the inaccuracies of classical imaging, first recommendations of modified operative treatment concepts have been made. When there is complete remission (cCR) on imaging the international multidisciplinary working group of the BIG-NABCG (Breast International Group-North American Breast Cancer Group) recommends surgical removal of the centre of the tumour only, this being marked with a clip before NACT [28]. Thus, only the residual tumour remaining after NACT defines operative target volume. However, the now frequently discussed question then arises whether surgery should be performed at all in the absence of detectable residual tumour.

Metabolic and vascular effects produced by NACT, i.e. functional changes, are not demonstrated on classical imaging but only possible with functional imaging: For example changes in the 
- Table 3 False negative rates and negative predictive values for predicting pathological complete remission in the breast using mammography, ultrasound and magnetic resonance imaging [4].

\begin{tabular}{|c|c|c|c|c|c|c|c|}
\hline \multirow[t]{2}{*}{ Study } & \multirow[t]{2}{*}{$\mathbf{n}$} & \multicolumn{2}{|c|}{ Mammography } & \multicolumn{2}{|c|}{ Ultrasound } & \multicolumn{2}{|l|}{ MRI } \\
\hline & & NPV (\%) & FNR (\%) & NPV (\%) & FNR (\%) & NPV (\%) & FNR (\%) \\
\hline Schott et al. [18] & 43 & 91 & 9 & 91 & 9 & 94 & 6 \\
\hline Peintinger et al. [19] & 162 & 93 & 7 & & & - & - \\
\hline Chen et al. [20] & 51 & - & - & - & - & 74 & 26 \\
\hline Bhattacharyya et al. [21] & 32 & - & - & - & - & 96 & - \\
\hline Keune et al. [22] & 192 & 86 & - & 85 & - & - & - \\
\hline Croshaw et al. [23] & 61 & 30 & 70 & 33 & 67 & 44 & 56 \\
\hline De Los Santos et al. [16] & 746 & - & - & - & - & $47^{\mathrm{a}}$ & - \\
\hline Schaefgen et al. [17] & 143 & 52 & 13 & 51 & 24 & 60 & 4 \\
\hline
\end{tabular}

morphology and perfusion of the tumour area can be demonstrated on dynamic contrast-enhanced magnetic resonance imaging (MRI). The precision of MRI in estimating tumour response to NACT varies by tumour subtype, being most accurate for estrogen receptor (ER) negative/HER2 positive and triple negative tumours (NPV 60-62\%) and least accurate for luminal tumours [16,29]. Promising results have also been shown for diffusion weighted imaging and nuclear medicine imaging techniques. Positron emission tomography (PET) and computer tomography (CT) can detect changes in glucose metabolism with a sensitivity of $84 \%$ (range $78-88 \%$ ) and an average specificity of 66\% (range 62$70 \%$ ). The accuracy of PET/CT for predicting PCR seems to depend on tumour subtype: highest sensitivity for ER negative and triple negative tumours [30].

\section{Minimally Invasive Diagnosis of Pathological Complete Remission}

In view of suboptimal imaging, attempts have been made to improve investigation to enable inclusion of only the patient group with pCR following NACT in studies of adapting locoregional management. In a study from 2007 Clouth et al. [31] evaluated a patient collective with complete remission clinically and on imaging after receiving NACT. In addition to axillary surgery each patient underwent multiple punch biopsies. Patients in whom the biopsies were free of tumour, thus presumptively diagnosed as $P C R$, were treated with radiotherapy alone and had no further breast surgery. Patients in whom biopsy detected tumour had breast conserving surgery or mastectomy followed by radiotherapy. The local recurrence rate in patients with PCR was $12.5 \%$ (two out of 16 patients) at an average of 33.5 months (10.6\% [eight out of 75 patients] in the comparison group of operated patients). This high local recurrence rate without breast surgery is unacceptable, but the significance of these results is questionable in view of the small study collective. Nevertheless, the following methodological problems regarding the biopsies in this study should be noted:
The punch biopsies were not performed under image guidance but rather arbitrarily in the (former) tumour-affected breast quadrant. Absence of tumour in such biopsy specimens cannot be regarded as equivalent to $P C R$ in the breast since areas of residual tumour may have been missed ("sampling error"). Thus, this study was also unsuccessful in identifying the patient collective with PCR. "Sampling error" should be kept as low as possible. Modern localisation methods and clip markers, implanted in the tumour area before NACT is commenced, can achieve this. In addition, research must find a method of assessing the representativity of biopsy material (taken from former tumour area or not) to allow evaluation of the actual accuracy of biopsy methods.

Recently various study groups have attempted to set up studies that implement minimally invasive biopsy methods for more exact diagnosis of complete remission following NACT. These studies have arisen from the motivation to be able to avoid breast surgery after NACT when PCR is certain, and have produced some promising results $[16,32]$.

A number of studies have shown the superiority of the vacuum biopsy over other minimally invasive biopsy methods. Both fine needle biopsy (NPV 63\%, FNR 52\% [33]) and punch biopsy (NPV $70.2 \%$, FNR 60.9\% [34]) have achieved worse diagnostic accuracy than vacuum biopsy in comparative studies. One of the first prospective pilot studies on ultrasound guided vacuum biopsy from the University of Heidelberg achieved very pleasing results (NPV $94.4 \%$ and FNR $4.8 \%$ when tissue samples underwent histopathological testing for representativity) ([3] Clinicaltrials.gov NCT02575612). The MD Anderson Cancer Center recently published a similar study with effectively identical results (NPV $90 \%$ and FNR 10\%) ("A Clinical Feasibility Trial for Identification of Exceptional Responders in Whom Breast Cancer Surgery Can Be Eliminated Following Neoadjuvant Systemic Therapy" [Clinicaltrials.gov NCT02455791] [33]). The Netherlands Cancer Institute Amsterdam, the University of Birmingham and the multicentre NRG Oncology Group are all currently conducting similar studies evaluating the diagnostic accuracy of minimally invasive biopsy methods [35]. A prospective multicentre confirmatory 
study that started in Germany in 2017 will evaluate the diagnosis PCR in 600 patients using VAB ("RESPONDER - Diagnosis of pathological complete Response by vacuum-assisted Biopsy after Neoadjuvant chemotherapy in breast cancer", Clinicaltrials.gov NCT02948764). Ultrasound- or stereotactic-guided vacuum biopsy of the intramammary lesion is performed after neoadjuvant therapy and assessed histopathologically. Thereafter, consistent with current guidelines, every patient is operated. The study endpoint is the false negative rate (FNR) of VAB compared to the pathological diagnosis of the surgical tissue specimen. In addition, a subgroup analysis will be undertaken to objectify criteria that influence the representativity of VAB. This study is currently in the recruiting phase in 23 breast centres. On the basis of these results future studies on the therapeutic benefits of surgery in cases of pCR are conceivable.

\section{Conflict of Interest}

The authors declare that they have no conflict of interest.

\section{References}

[1] Ellis P, Smith I, Ashley S et al. Clinical prognostic and predictive factors for primary chemotherapy in operable breast cancer. J Clin Oncol 1998; 16: $107-114$

[2] Ring A, Webb A, Ashley S et al. Is surgery necessary after complete clinical remission following neoadjuvant chemotherapy for early breast cancer? J Clin Oncol 2003; 21: 4540-4545

[3] Heil J, Schaefgen B, Sinn P et al. Can a pathological complete response of breast cancer after neoadjuvant chemotherapy be diagnosed by minimal invasive biopsy? Eur J Cancer 2016; 69: 142-150

[4] van la Parra RF, Kuerer HM. Selective elimination of breast cancer surgery in exceptional responders: historical perspective and current trials. Breast Cancer Res 2016; 18: 28

[5] De Lena M, Varini M, Zucali R et al. Multimodal treatment for locally advanced breast cancer. Result of chemotherapy-radiotherapy versus chemotherapy-surgery. Cancer Clin Trials 1981; 4: 229-236

[6] Perloff M, Lesnick G], Korzun A et al. Combination chemotherapy with mastectomy or radiotherapy for stage III breast carcinoma: a Cancer and Leukemia Group B study. J Clin Oncol 1988; 6: 261-269

[7] Scholl SM, Pierga JY, Asselain B et al. Breast tumour response to primary chemotherapy predicts local and distant control as well as survival. Eur J Cancer 1995; 31A: 1969-1975

[8] Touboul E, Buffat L, Lefranc JP et al. Possibility of conservative local treatment after combined chemotherapy and preoperative irradiation for locally advanced noninflammatory breast cancer. Int J Radiat Oncol Biol Phys 1996; 34: 1019-1028

[9] Mauriac L, MacGrogan G, Avril A et al. Neoadjuvant chemotherapy for operable breast carcinoma larger than $3 \mathrm{~cm}$ : a unicentre randomized trial with a 124-month median follow-up. Institut Bergonie Bordeaux Groupe Sein (IBBGS). Ann Oncol 1999; 10: 47-52

[10] Daveau C, Savignoni A, Abrous-Anane S et al. Is radiotherapy an option for early breast cancers with complete clinical response after neoadjuvant chemotherapy? Int J Radiat Oncol Biol Phys 2011; 79: 1452-1459

[11] Chagpar AB, Middleton LP, Sahin AA et al. Accuracy of physical examination, ultrasonography, and mammography in predicting residual pathologic tumor size in patients treated with neoadjuvant chemotherapy. Ann Surg 2006; 243: 257-264
[12] Shin HJ, Kim HH, Ahn JH et al. Comparison of mammography, sonography, MRI and clinical examination in patients with locally advanced or inflammatory breast cancer who underwent neoadjuvant chemotherapy. $\mathrm{Br}$ ] Radiol 2011; 84: 612-620

[13] Marinovich ML, Houssami N, Macaskill P et al. Meta-analysis of magnetic resonance imaging in detecting residual breast cancer after neoadjuvant therapy. J Natl Cancer Inst 2013; 105: 321-333

[14] Marinovich ML, Houssami N, Macaskill P et al. Accuracy of ultrasound for predicting pathologic response during neoadjuvant therapy for breast cancer. Int J Cancer 2015; 136: 2730-2737

[15] Eisenhauer EA, Therasse P, Bogaerts J et al. New response evaluation criteria in solid tumours: revised RECIST guideline (version 1.1). Eur J Cancer 2009; 45: 228-247

[16] De Los Santos JF, Cantor A, Amos KD et al. Magnetic resonance imaging as a predictor of pathologic response in patients treated with neoadjuvant systemic treatment for operable breast cancer. Translational Breast Cancer Research Consortium trial 017. Cancer 2013; 119: 1776-1783

[17] Schaefgen B, Mati M, Sinn HP et al. Can routine imaging after neoadjuvant chemotherapy in breast cancer predict pathologic complete response? Ann Surg Oncol 2016; 23: 789-795

[18] Schott AF, Roubidoux MA, Helvie MA et al. Clinical and radiologic assessments to predict breast cancer pathologic complete response to neoadjuvant chemotherapy. Breast Cancer Res Treat 2005; 92: 231-238

[19] Peintinger F, Kuerer HM, Anderson K et al. Accuracy of the combination of mammography and sonography in predicting tumor response in breast cancer patients after neoadjuvant chemotherapy. Ann Surg Oncol 2006: 13: 1443-1449

[20] Chen JH, Feig B, Agrawal G et al. MRI evaluation of pathologically complete response and residual tumors in breast cancer after neoadjuvant chemotherapy. Cancer 2008; 112: 17-26

[21] Bhattacharyya M, Ryan D, Carpenter R et al. Using MRI to plan breastconserving surgery following neoadjuvant chemotherapy for early breast cancer. Br J Cancer 2008; 98: 289-293

[22] Keune JD, Jeffe DB, Schootman M et al. Accuracy of ultrasonography and mammography in predicting pathologic response after neoadjuvant chemotherapy for breast cancer. Am J Surg 2010; 199: 477-484

[23] Croshaw R, Shapiro-Wright H, Svensson E et al. Accuracy of clinical examination, digital mammogram, ultrasound, and MRI in determining postneoadjuvant pathologic tumor response in operable breast cancer patients. Ann Surg Oncol 2011; 18: 3160-3163

[24] Adrada BE, Huo L, Lane DL et al. Histopathologic correlation of residual mammographic microcalcifications after neoadjuvant chemotherapy for locally advanced breast cancer. Ann Surg Oncol 2015; 22: 1111-1117

[25] Matsuo K, Fukutomi T, Watanabe T et al. Concordance in pathological response to neoadjuvant chemotherapy between invasive and noninvasive components of primary breast carcinomas. Breast Cancer 2002; 9: $75-81$

[26] Vinnicombe S], MacVicar AD, Guy RL et al. Primary breast cancer: mammographic changes after neoadjuvant chemotherapy, with pathologic correlation. Radiology 1996; 198: 333-340

[27] Fadul D, Rapelyea J, Schwartz AM et al. Development of malignant breast microcalcifications after neoadjuvant chemotherapy in advanced breast cancer. Breast J 2004; 10: 141-145

[28] Bossuyt V, Provenzano E, Symmans WF et al. Recommendations for standardized pathological characterization of residual disease for neoadjuvant clinical trials of breast cancer by the BIG-NABCG collaboration. Ann Oncol 2015; 26: 1280-1291

[29] Loo CE, Straver ME, Rodenhuis S et al. Magnetic resonance imaging response monitoring of breast cancer during neoadjuvant chemotherapy: relevance of breast cancer subtype. J Clin Oncol 2011; 29: 660-666

[30] Wang Y, Zhang C, Liu J et al. Is 18F-FDG PET accurate to predict neoadjuvant therapy response in breast cancer? A meta-analysis. Breast Cancer Res Treat 2012; 131: 357-369 
[31] Clouth B, Chandrasekharan S, Inwang R et al. The surgical management of patients who achieve a complete pathological response after primary chemotherapy for locally advanced breast cancer. Eur J Surg Oncol 2007; 33: 961-966

[32] Rea D, Tomlins A, Francis A. Time to stop operating on breast cancer patients with pathological complete response? Eur J Surg Oncol 2013; 39: 924-930
[33] Kuerer HM, Rauch GM, Krishnamurthy S et al. A clinical feasibility trial for identification of exceptional responders in whom breast cancer surgery can be eliminated following neoadjuvant systemic therapy. Ann Surg 2017. doi: $10.1097 /$ SLA. 0000000000002313

[34] Heil J, Kummel S, Schaefgen B et al. Diagnosis of pathological complete response to neoadjuvant chemotherapy in breast cancer by minimal invasive biopsy techniques. $\mathrm{Br}$ J Cancer 2015; 113: 1565-1570

[35] Kuerer HM, Vrancken Peeters M, Rea DW et al. Nonoperative management for invasive breast cancer after neoadjuvant systemic therapy: conceptual basis and fundamental international feasibility clinical trials. Ann Surg Oncol 2017. doi:10.1245/s10434-017-5926-z 